\title{
Library Equipment Specifications, a Dialogue
}

\author{
BY ROBERT N. BROADUS
}

$Q$. WHY does the writing of specifications for library furniture and equipment seem to present such knotty problems?

$A$. There are several respects in which this kind of merchandise is so unusual as to be out of the range ordinarily discussed in the standard treatises on purchasing procedure. For one thing, there are comparatively few reliable manufacturers who concern themselves with this product. Again, library equipment is much more technical than is generally realized. Certain details have to be spelled out, if the equipment is to function satisfactorily.

A third factor has to do with the comparative degree of flexibility possible in the manufacture of library equipment. To illustrate: on the general building contract, the architect writes careful specifications, the contract is awarded on the basis of the lowest responsive bid, and the builder is expected to follow the requirements completely. If an exterior facing of field stone is called for, no contender whines that this requirement is a handicap to his bidding, nor does the successful bidder try to substitute brick. The contractor is flexible. He can adapt easily to the specifications.

Hardware for the doors is a different problem. The manufacturer has far less flexibility than the general contractor. Because of the relatively small amount used in one library, any specification calling for variation in a firm's standard design is likely to eliminate that firm from the competition. This means, of course, that specifications for hardware have to
Mr. Broadus is Associate Professor of Library Science at Northern. Illinois University, DeKalb.

be very loose if the owner is willing to accept the offerings of a wide range of suppliers, but that if a specific design or quality is the only one acceptable, then the specification may limit the possibility to one manufacturer. Indeed, it is not uncommon to remove hardware from the arena of competitive bidding.

From the standpoint of flexibility, library furniture and equipment manufacturers normally fall between these two. The bidder's costs are less (quality for quality) if he can follow his standard design and manufacture. Yet he is able to make certain adaptations without seriously affecting his total bid. For instance, in a $\$ 100,000$ steel book stack contract, a specification requiring a manufacturer to add one punch for each otherwise standard end panel would be a handicap, but it would not be a disastrous one. On wood equipment also, since each piece involves some hand work, a small variation is possible without prohibitive costs.

There are some firms which, having excellent engineering staffs, are more adaptable than others. Furthermore, some manufacturers are adept at using standard parts to create new designs and functions with a minimum of special additions. On the other hand, it is not unfair to state that the flexibility of some companies is limited to the pirating of ideas already developed by their competitors. 
It may be added that the sizable modern library planned with any imagination at all will require some equipment items of special manufacture. It cannot be limited to the standard offerings of any company or group of companies.

These are some of the factors which make library equipment specifications different in kind from those used on the building contract, and from those used to buy office desks and classroom chairs.

$Q$. What is the purpose of a specification?

$A$. Perhaps we should start with the obvious: a good specification is a document which insures that the owner will obtain equipment of the design and quality he needs or wants at the lowest price. It is amazing how often this assumption is overlooked.

$Q$. But I thought a specification was good if it attracted a great many bidders.

$A$. A large list of bidders is desirable, but as a means, not as an end. The fact that numerous firms submit bids may indicate keen competition, and competition usually means a lower price. But such a conclusion does not always hold. A project may attract many bidders merely because the specifications have such loopholes that anyone can bid with the expectation of a good profit.

Contrary to some views, it is only common sense that the library itself will be better served by two responsive bids in the neighborhood of $\$ 215,000$ than by eight bids ranging from $\$ 223,000$ through $\$ 287,000$ assuming (unlikely thought) that the products be exactly equal in value to the library. Others may say, of course, that newspaper accounts of eight bids are worth the $\$ 8,000$ in public relations value.

$Q$. But shouldn't a specification be neutral, so that many different firms can bid?

$A$. The specification should be neutral to the extent that neutrality serves the purpose of getting the material needed at the lowest cost. The chances are that "neutral" specifications will attract more bidders, and hence increase the element of competition. But there is an inverse relationship between neutrality and the likelihood of obtaining the precise equipment needed. As needs are defined more sharply, the specifications are tightened, and the degree of neutrality is reduced.

Let me illustrate: If a library specifies that card catalog trays be made of wood, then all firms offering metal only are quickly eliminated. Neutrality has been sacrificed (most librarians would say justifiably) for the sake of obtaining suitable equipment.

Of course a performance specification (e.g. "The joint shall stand 100 pounds of pressure applied at right angles to the length of the tray"-not "The joint shall be secured by six drops of Elmer's glue distributed evenly") can solve many issues of this kind and should be used wherever feasible, but if wood is required it is easier to be explicit rather than to write such detailed performance requirements that all other common materials are eliminated. Furthermore, a performance specification is only as strong as the tests which it proposes to apply to the delivered product. These tests can be difficult to devise and expensive to administer. ${ }^{1}$

So then, we have to give up the idea of complete neutrality if we expect to buy equipment which is even remotely like the kind we want.

$Q$. But can't we still be neutral in the matter of sizes and quality, so that we assure ourselves of a dozen bids?

$A$. Even here the problem is not simple. Let us take the question of size as a crude illustration, since this is a thing we can picture easily. Let us say that the following firms offer library reading tables of the lengths given:

Company A, 59 inches

Company B, 60 inches

${ }^{1}$ Frazier G. Poole, "Performance Standards and Specifications in the Library Economy," Library Trends, XI (April 1963), 436-44. 
Company C, 64 inches

Company D, 66 inches

Company E, 67 inches

In the interest of neutrality, we may say that the tables must be 63 inches long. If we do, we probably shall get five bids reasonably close together, but all five will be a little higher than they should be, for our specification calls for a size that is special (nonstandard) to all. No one bidder can give us his best price.

Let's try another possibility: we shall specify that any length 59 through 67 inches will be acceptable. If our furniture layout is so loose as to allow this much tolerance in size, it is poor to begin with. But more to the point at issue: such a specification is not neutral, for it clearly favors the manufacturer of the smallest (supposedly cheapest) table. In the same way, it penalizes the manufacturer of the largest by saying that his table is no more acceptable than the smallest.

It would be far more practical to forget neutrality and specify tables of optimum size for our particular floor plan (e.g. not less than 66 inches nor more than 67 inches in length). Thus we gain the probability of two favorable bids rather than five unfavorable ones. Such a specification does not prohibit companies $\mathrm{A}, \mathrm{B}$, and $\mathrm{C}$ from offering tables which are "special" to them. One of the firms may be able to adapt so skillfully as to present the low bid. This possibility serves as a warning to companies D and $\mathrm{E}$ to keep their prices in line.

I use this oversimplified example for the sake of clarity. The same principles hold with those factors which are more difficult to describe; such as quality of materials, construction, finish, durability, and attractiveness.

$Q$. But that seems so unfair to some bidders!

$A$. That I deny. Let me remind you again of the basic purpose of the specifications. The owner has no obligation to need what a manufacturer can supply; it is the company's responsibility to provide what the library needs. A specification calling for glass windows (or a performance specification which clearly eliminates all products save glass and similar materials) can hardly be called "unfair" to the waxed paper industry.

I'm glad, however, that you consider fairness so important. The specifications and bidding procedures most certainly should be fair to all concerned. Fairness is assured when all firms bid on the same things, with confidence that the specifications will be adhered to- that no specification will be altered after the opening of bids. Unfairness is practiced when the owner calls for bids on one quality, then accepts a bid based on a different quality.

$Q$. Should not each vendor have the right to try to sell his product after the bids are opened?

$A$. All "selling" should be done before the specifications are completed. If the specifications are to do their job, they must represent the best information the owner has been able to assemble, both from his own resources and from presentations and arguments of salesmen. Then each firm bids on the same thing, and there is no attempt to "sell" changes in specifications after the bid opening.

Though most bid documents contain the clause "The owner reserves the right to waive formalities and to purchase any product best suited to owners' needs," or words to that effect, this statement should not give the owner license to alter the specification to favor any firm after the bids have been received.

$Q$. But don't we need to know the approximate prices of all the features offered by the various companies before deciding which we can afford to specify?

$A$. Should it be necssary, alternates may be called for in the specifications. To take another example, oversimplified for the sake of clarity, let us say that the owner prefers walnut, but thinks he may have to settle for maple, hence needs to get firm quotations on both. In such case, it should be clear that all bidders are 
invited to submit prices on either or both species of wood and that the price for each must be plainly indicated. To call for bids on walnut only, then waive the specification and purchase the equipment of a vendor who, on his own, proposes the alternate of maple (whatever the price differential) is grossly unfair to the other bidders-those who had no opportunity to bid on maple. It may be interpreted as downright dishonesty.

$Q$. Why not let each firm bid on all the alternates it can offer?

$A$. Most firms could not list in reasonable space all the possible variations in materials, construction, and design they are capable of producing. No owner could make an intelligent tabulation of these masses of alternates. The owner, not the bidder, is the one who knows what is required. He should not try to avoid the responsibility of stating his needs clearly.

$Q$. But let's back up: if your specifications happen to be easier for one or two manufacturers than for others, and if you buy strictly according to the specifications, aren't you leaving yourself open to the charge of rigging?

$A$. Only one firm will get each part of the contract. All others are going to be disappointed and are likely to express that disappointment in some way-appropriate or otherwise. If any potential bidder thinks the specifications unfair, his protests should be heard beforehand, and then the owner can make whatever corrections are wise before the documents are released for bid. After the specifications are complete, each firm can decide whether to invest time and money in submitting a bid. The proprietor of Sam's Sheet Metal Shop may be disappointed that he is not equipped to bid on wood bookstacks. He has invested no money, however, and he has no reasonable ground for complaint.

Let's look at the other side: a firm expends time figuring a bid closely according to specifications, goes to the expense of furnishing samples (perhaps making them up especially for the occasion), and then loses the contract because, after the bid opening, specifications are changed to favor a lower priced (or higher priced) competitor. Here is just ground for a serious accusation. The unfairness may be rectified, but only in part, by throwing out all bids and allowing each firm to submit a new bid on the revised specifications. This procedure inflicts an extra cost on the owner and all others involved, and it delays completion of the contract.

Incidentally, the bid form should provide that the successful contender post a performance bond stating clearly that the bonding company will be responsible for the completion of the contract regardless of the final cost of performance. Surely librarians have learned from this kind of experience with such outfits as lowbidding periodical subscription agencies, so that this warning need not be elaborated. Libraries have too long been considered soft touches by "low" bidders who will not, or actually cannot, deliver the goods.

$Q$. Why can't we just list the equipment by the catalog number of an acceptable manufacturer, and say that this item "or equal" is to be supplied?

$A$. Such a specification says practically nothing. Who can define "or equal"? Everything in the universe is equal to everything else, at least in the sense of being in existence, while no two objects in the universe are absolutely alike. Think of the dispute about the meaning of "equal" in the Declaration of Independence! If a specification can't spell out why a certain cataloged item is acceptable -what aspects of it are necessary and what irrelevant-then the effort should not be called a specification at all. ${ }^{2}$

Your fear of rigging, by the way, might be more appropriate here.

"See the panel discussion "Specifieation Writing and Bidding Procedures for Furniture and Shelving," ALA Library Equipment Institute, Library Furniture and Equipment (Chicago: ALA, 1963), p. 34. 
$Q$. Should specifications be prepared by an equipment contractor?

$A$. This is a tough one. In favor of the practice are:

1. The equipment contractor has more up-to-date information about planning and manufacture than any one else readily available to the library, even at a healthy fee. He has access to the latest research and knows what new products are to be made available in the immediate future.

For the average librarian or purchasing agent to write a good specification requires about as much research as completing a master's thesis, especially if the contract be large and the equipment complex.

2. If an equipment contractor writes the specifications the owner is assured of at least one responsive bid.

On the negative side there are these major considerations:

1. The equipment manufacturer, unless unusually well qualified, tends to pour all libraries (particularly those of schools) into the same mold without imagination or originality. The same charge certainly may be brought against architects, however, even the best.

2. The equipment maker or dealer will tend to write specifications which favor his own firm and may so shape them as to prohibit bids from competitors. This tendency is not necessarily intentional; naturally the firm is accustomed to its own equipment and considers it superior, or at least adequate.

Fortunately, these two problems can be solved. In dealing with the first one, the librarian must work closely with the planners and specification writers if a decent job is to result. If the architect's blueprints are turned over to the planners with no statement of program or other instructions, the results will be crudejustifiably so.

As for the second, the specification writers should be told clearly what quali- ties are needed, even if they vary from this particular manufacturer's standard. Presumably the librarian will work with the firm he believes best able to perform a contract of the kind under consideration; thus such exceptions can be held to a minimum. Better yet, the discussions incidental to such planning may result in new products, thus becoming an advantage to both library and manufacturer. The librarian may be stimulated to express freely his requirements and wishes, while the equipment specialist suggests ways to meet these requirements within the limits of the achievable.

It should be understood that the owner will scrutinize the preliminary draft carefully to be sure the specifications are as competitive as possible, consistent with the library's needs and purposes. It should be agreed further that other firms will be allowed to try to sell variations favorable to themselves, and that some of these suggestions may be incorporated in the final specifications.

Before embarking on such an expensive and time-consuming project, it would be wise of the librarian, in the interest of fairness both to himself and to the planners, to obtain assurances, preferably in writing, from those who are to make the final purchasing decisions that the completed specifications will be held inviolate and that no deviations will be permitted.

With these allowances, there is no reason for reliance on an equipment contractor defeating the purpose of the specifications as stated in the beginning.

Adequate specifications then involve a great deal of thought and effort, but they represent time well spent, even though perfect clarity and justice be unobtainable. Such documents assure that bidding will be fair and that the library will receive the equipment it needs at the lowest price. The general application of this approach also should make a positive contribution to the health of the library equipment industry. 